\title{
Line Conditioner Device
}

National Cancer Institute

\section{Source}

National Cancer Institute. Line Conditioner Device. NCI Thesaurus. Code C50033.

An electronic device designed to improve the output quality of a power source, typically by smoothing the output voltage. 